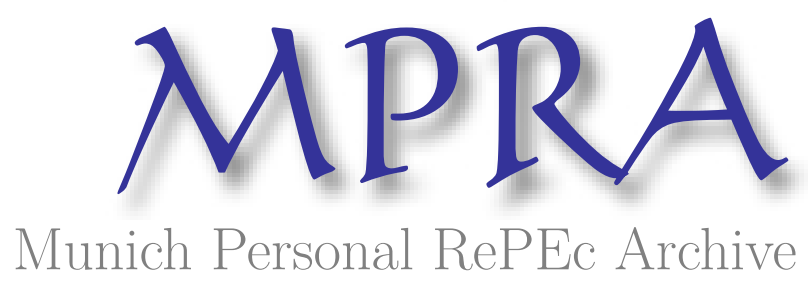

\title{
Political competition in hard times
}

Zudenkova, Galina

1 May 2011

Online at https://mpra.ub.uni-muenchen.de/30943/

MPRA Paper No. 30943, posted 17 May 2011 23:07 UTC 


\title{
Political Competition in Hard Times*
}

\author{
Galina Zudenkova ${ }^{\dagger}$ \\ Department of Economics and CREIP, Universitat Rovira i Virgili
}

May 17, 2011

\begin{abstract}
This paper analyzes a spatial model of political competition between two policymotivated parties in hard times of crisis. Hard times are modeled in terms of policymaking costs carried by a newly elected party. The results predict policy divergence in equilibrium. If the ideological preferences of parties are quite diverse and extreme, there is a unique equilibrium in which the parties announce symmetric platforms and each party wins with probability one half. If one party is extreme while the other is more moderate, there is a unique equilibrium in which the parties announce asymmetric platforms. If the preferred policies of the parties are not very distinct, there are two equilibria with asymmetric platforms. An important property of equilibrium with asymmetric platforms is that a winning party necessarily announces its most preferred policy as a platform.

JEL classification: D72.

Keywords: Spatial model; Political competition; Two-party system; Policy-motivated parties; Hard times; Crisis.
\end{abstract}

\footnotetext{
${ }^{*}$ The author is grateful to Antonio Cabrales, Luis Corchón, Matthias Dahm, Ignacio Ortuño Ortín, Antonio Osório-Costa, Xose-Luis Varela-Irimia, and seminar and conference participants at several institutions for useful comments and suggestions. FPI Grant BES-2005-10017 and Project ECO2008-02738 of the Spanish Ministry of Science and Innovation are gratefully acknowledged. An earlier draft of this paper was circulated under the title "Wittman Model with Costly Policy Implementation". The usual disclaimer applies.

${ }^{\dagger}$ Department of Economics, Universitat Rovira i Virgili, Av. de la Universitat 1, Reus 43204, Spain. E-mail address: galina.zudenkova@gmail.com.
} 
A pre-election interview of Artur Mas, the Catalonian regional president: ${ }^{1}$

- Do you agree that in these hard times, very hard times that the world faces now, it is even more difficult to govern?

- Yes, definitely. It is more difficult to govern because the circumstances, all of them, are more complicated.

\section{Introduction}

Is political competition affected by an economic, political or financial crisis? Do political parties adjust their platforms in hard times? Do they tend to announce more extreme or more moderate platforms? To answer these questions, I develop a one-period spatial model of political competition in hard times in a two-party system. I consider two well-established policy-motivated parties with opposite policy preferences. The policy preferences of voters are symmetric around the preferred policy of the median voter. The parties run in an election and commit to their announced platforms, and the party that wins the majority of votes wins the election (plurality rule). The novelty of the model is in introducing a hard-times assumption. There are certain factors that characterize policy-making in hard times of crisis. First, policymaking becomes more complicated. Indeed, crisis brings unemployment, increasing public debt, inflation, bankruptcies, etc. A winning political party faces a much greater number of more complicated problems to solve in times of recession than in boom times. Second, in hard times a governing party is likely to be accused of incompetence. The public tends to blame policy-makers for economic events beyond their control. In hard times, therefore, a governing party might suffer a loss of reputation. I formalize such hard-times conditions in terms of a fixed policy-making cost that a winning party carries once in office. In hard times, parties therefore face a trade-off between ideology and its price, while in good times the trade-off is between ideology and winning.

I first show that in hard times there is no equilibrium with policy convergence. The reason is that no party wants to carry the cost of a policy that can be implemented by another party. Second, if policy-making is very costly, each party would prefer the rival's policy platform to its own (very costly) platform and thus would tend to announce a platform that is more extreme than that of its rival. As a result, the parties announce the most extreme opposite

\footnotetext{
${ }^{1}$ This was translated from Spanish by the author. The interview was held on November 12, 2010. The video is available online at http://www.lasexta.com/sextatv/buenafuente/en_las_relaciones_entre_zapatero _y_yo_estamos_en_el_frio__frio/183131/191. The original in Spanish:

- ¿Está de acuerdo que en estos tiempos tan difíciles, muy difíciles mundiales todavía es más difícil gobernar?

- Sí, señor, sí. Ahora es más difícil gobernar porque las circunstancias son más complicadas todas ellas.
} 
policies and each wins with probability one half. For a moderate policy-making cost, there are either one or two equilibria with policy divergence. If the distance between the most preferred policies (MPPs) of the parties does not exceed the policy-making cost, there are two equilibria with asymmetric platforms, whereby the winning party announces its MPP while the losing party picks any policy from a certain equilibrium interval. Therefore, if the ideologies of the parties are not very distinct, there is one equilibrium in which the party with a more moderate preferred policy announces it as a platform and wins the election, and another equilibrium in which the party with a less moderate preferred policy announces it as a platform and wins the election. However, if the distance between the MPPs exceeds the policy-making cost, there is a unique equilibrium. If the MPPs are extreme, this is an equilibrium with symmetric platforms in which each party wins with probability one half and the announced platforms are more moderate than the MPPs. If one party is extreme and the other party is relatively more moderate, this is an equilibrium with asymmetric platforms in which the more moderate party announces its preferred policy and wins the election, while the losing party announces any policy from a certain equilibrium interval. Thus, if the ideologies of the parties are diverse there is no equilibrium with asymmetric platforms in which the more extreme party announces its preferred policy and wins the election. The intuition is that if this were the case, the losing party (which has a more moderate preferred policy) could deviate, announcing its preferred policy and winning the election; since the preferred policies of the parties are quite diverse, such a deviation would be profitable.

My results emphasize an important feature of political competition in hard times of crisispolicy divergence. Indeed, in times of costly policy-making, a policy-motivated party would bear such a cost only if its gains in terms of policy outcomes are large enough, implying that its announced policy is quite different from that of the other party. Another important characteristic of political competition in hard times in a two-party system is the existence of equilibria with asymmetric platforms in which a winning party announces its MPP. Intuitively, if the winning party announces a platform different from its MPP then it can profitably deviate to the direction of its preferred policy and still win the election. Thus, in an equilibrium with asymmetric platforms a winning party necessarily announces its MPP.

The spatial model of political competition adopted here goes back to the seminal work of Downs (1957), who emphasized policy convergence in a two-party system with officemotivated parties. Palfrey (1984) considered entry by a third vote-maximizing party that announces its platform after observing the choices of the other two office-motivated parties. The third party loses in equilibrium. Its entry, however, affects the policy platforms announced by the other two parties, leading to policy divergence. Feddersen et al. (1990) 
further modified a spatial model of political competition allowing office-motivated candidates to make decisions regarding entry, as well as policy platforms, and assuming strategic voting. They showed that in equilibrium, all entrants adopt the ideal policy of the median voter. A further step was taken by Wittman (1977, 1983, 1990), Calvert (1985), Alesina (1988) and Roemer (1994), who considered policy-motivated parties. It has been shown that under full commitment, two policy-motivated parties announce convergent platforms when the distribution of the voters' ideal policies is known, and divergent platforms otherwise (Wittman 1977, Calvert 1985, Roemer 1994). Alesina (1988) argued that if the parties cannot commit to platforms, then in equilibrium each party carries out its preferred policy. Banks (1990) developed a two-party model of electoral competition in which implementation of a policy different from the announced policy is costly to the winning party; moreover, these costs increase with the difference between the implemented and announced policies. The model predicts policy divergence for sufficiently high values of these costs. Osborne and Slivinski (1996) and Besley and Coate (1997) independently developed a citizen-candidate model in which citizens decide whether or not to run as candidates in an election. Similar to Alesina (1988), they assumed that candidates cannot commit to platforms, and so announce their preferred policies in equilibrium. They show that, depending on the parameter values, there might be equilibria with one, two, three or more candidates running.

This paper complements the aforementioned literature by analyzing political competition between two policy-motivated parties under assumption of costly policy-making. It is important to emphasize that I consider a two-party system in which two well-established parties definitely run in the election, and so make decisions only regarding policy platforms and not regarding entry. (Think of the US Democrats and Republicans, for example.) An analysis of entry decisions by parties is left for future research.

The remainder of the paper is organized as follows. Section 2 describes the model. Section 3 proceeds with the formal analysis. Finally, Section 4 concludes the paper.

\section{Model}

Consider a society inhabited by a large number (formally a continuum) of individuals, where the population mass is normalized to unity. Individuals differ in their preferences over a one-dimensional policy outcome $x$. The set of feasible policies is taken to be a closed interval $[0,1]$. For simplicity, individuals' MPP outcome is assumed to be distributed uniformly on $[0,1]$. The individuals have Euclidean preferences, i.e., their utility function is decreasing in the Euclidean distance between their MPP and an implemented policy. 
A policy outcome is determined through political competition and, in particular, through a competitive winner-takes-all election. Suppose that there are two well-established political parties that are major actors in the political arena and therefore definitely run in the election. The payoff function for party $i$, denoted by $\Pi_{i}, i=1,2$, depends on policy proposals $x_{1}$ and $x_{2}$ announced by the parties before the election, so $\Pi_{i}:[0,1]^{2} \rightarrow \mathbb{R}$. The function $\Pi_{i}\left(x_{1}, x_{2}\right)$ is defined explicitly in Section 2.1.

Definition 1. A political equilibrium is a pure strategy Nash equilibrium in the game played by the two parties. In other words, a political equilibrium is a policy pair $\left\{x_{1}^{*}, x_{2}^{*}\right\}$ such that

$$
\begin{array}{ll}
\Pi_{1}\left(x_{1}^{*}, x_{2}^{*}\right) \geq \Pi_{1}\left(x, x_{2}^{*}\right) & \forall x \in[0,1], \\
\Pi_{2}\left(x_{1}^{*}, x_{2}^{*}\right) \geq \Pi_{2}\left(x_{1}^{*}, x\right) & \forall x \in[0,1] .
\end{array}
$$

I assume not only complete information and zero abstention, but also full commitment such that a newly elected party will implement a policy it has announced before the election. Then, facing the two party proposals $x_{1}$ and $x_{2}$, individuals cast their votes for the one they prefer according to their Euclidean preferences. If voters are indifferent to the two announced policies, they vote for each party with equal probability. A party that wins the majority of votes wins the election. In the case of a tie, each party wins with probability one half. This, together with the assumption of no abstention, implies that the probability of party 1 winning the election, denoted by $p\left(x_{1}, x_{2}\right)$, is given by:

$$
p\left(x_{1}, x_{2}\right)=\left\{\begin{array}{lll}
1 & \text { if } \quad\left(x_{1}<x_{2}\right) \cap\left(x_{1}+x_{2}>1\right) \text { or }\left(x_{1}>x_{2}\right) \cap\left(x_{1}+x_{2}<1\right) \\
\frac{1}{2} & \text { if } \quad x_{1}=x_{2} \text { or }\left(x_{1} \neq x_{2}\right) \cap\left(x_{1}+x_{2}=1\right) \\
0 & \text { if } \quad\left(x_{1}<x_{2}\right) \cap\left(x_{1}+x_{2}<1\right) \text { or }\left(x_{1}>x_{2}\right) \cap\left(x_{1}+x_{2}>1\right) .
\end{array}\right.
$$

The parties are therefore the only strategic players in this framework. Once they announce policy proposals $x_{1}$ and $x_{2}$, the election outcome is decided.

The objective of this paper is to analyze political competition between two policy-motivated parties in hard times of crisis. I search for political equilibria under the assumption of policymotivated parties and hard-times conditions. These assumptions are stated in detail in the following subsection.

\subsection{Party Payoff Functions}

The parties are policy-motivated in the sense of having preferences over the policy space. $\alpha_{i}$ denotes the MPP of party $i, i=1,2$. The parties have opposite policy preferences. To formalize this idea, it is assumed that $\alpha_{1}<\frac{1}{2}<\alpha_{2}$. Party 1 might then be referred to as a 
left-wing party and party 2 as a right-wing party. The utility of party $i$ is decreasing in the Euclidean distance between its MPP $\alpha_{i}$ and an implemented policy, say $x$ :

$$
-\left|x-\alpha_{i}\right|
$$

Suppose that society faces hard times of crisis (e.g., recession). There are certain features that distinguish policy-making in hard times: first, policy implementation becomes more challenging and second, a governing party is likely to suffer reputation loss and be accused of incompetence. To formalize such hard-times conditions, I assume that the winning party, once in office, carries a fixed policy-making cost $C>0$ in terms of utility. This can be interpreted as a cost for policy implementation or a reputational cost. ${ }^{2}$

I now specify the party payoffs, i.e., their expected utilities:

$$
\begin{aligned}
& \Pi_{1}\left(x_{1}, x_{2}\right)=p\left(x_{1}, x_{2}\right)\left(-\left|x_{1}-\alpha_{1}\right|-C\right)+\left(1-p\left(x_{1}, x_{2}\right)\right)\left(-\left|x_{2}-\alpha_{1}\right|\right), \\
& \Pi_{2}\left(x_{1}, x_{2}\right)=p\left(x_{1}, x_{2}\right)\left(-\left|x_{1}-\alpha_{2}\right|\right)+\left(1-p\left(x_{1}, x_{2}\right)\right)\left(-\left|x_{2}-\alpha_{2}\right|-C\right),
\end{aligned}
$$

where $p\left(x_{1}, x_{2}\right)$ is the probability that party 1 wins the election, defined in $(2.1)$. In the following section, I search for political equilibria $\left\{x_{1}^{*}, x_{2}^{*}\right\}$ when the payoff functions are as stated above.

\section{Analysis}

I start the analysis with the following proposition emphasizing the non-existence of political equilibrium with policy convergence.

Proposition 1. There is no political equilibrium with policy convergence.

Proof. This proposition is easily proved by contradiction. Suppose that in equilibrium the parties announce the same policy $x \in(0,1)$. Each party wins with probability one half and obtains a payoff of $-\left|x-\alpha_{i}\right|-\frac{C}{2}, i=1,2$. Each party, however, has an incentive to deviate in order to lose the election and to obtain a payoff of $-\left|x-\alpha_{i}\right|$, saving the expected policy-making cost $\frac{C}{2}$. Therefore, $\{x, x\}$ is not a political equilibrium. Suppose further that in equilibrium the parties announce the same extreme policy 0 . The payoff of party $i$ in this case is equal to $-\alpha_{i}-\frac{C}{2}$. Party 2 , however, is better off deviating to $x_{2}=1$. This gives party 2 a payoff of $-\frac{1}{2}-\frac{C}{2}$, which is strictly greater than $-\alpha_{2}-\frac{C}{2}$ (since $\alpha_{2}>\frac{1}{2}$ ). Thus, $\{0,0\}$ is not a political equilibrium. By analogy, $\{1,1\}$ is not a political equilibrium as party 1 is

\footnotetext{
${ }^{2}$ When $C=0$, the model converges to a standard model of political competition with two policy-motivated parties as analyzed by Wittman (1990) and Calvert (1985).
} 
better off deviating to $x_{1}=0$; this yields a payoff of $-\frac{1}{2}-\frac{C}{2}$, which is strictly greater than $\alpha_{1}-1-\frac{C}{2}$ (since $\alpha_{1}<\frac{1}{2}$ ). There is therefore no political equilibrium with policy convergence.

Proposition 1 stresses an important feature of political competition in hard times-a lack of policy convergence. Indeed, why would two political parties with opposite policy preferences announce the same platform when policy-making is so costly? It makes no sense to carry the cost of a policy that can be implemented by the other party.

Proposition 1 therefore implies that in political equilibrium the parties announce divergent policies. In what follows, to prevent bizarre outcomes (such as announcement of a rightist platform by a left-wing party or vice versa), I restrict the set of choices available to the parties in the following way: $x_{1} \in\left[0, \frac{1}{2}\right], x_{2} \in\left[\frac{1}{2}, 1\right]$. Note, moreover, that for high policy-making costs, each party prefers a rival's platform to its own very costly platform, and thus has an incentive to announce the most extreme platform from its set of available policies. It is easy to show that for $C>1$, there is a unique political equilibrium in which the parties announce extreme symmetric platforms $\{0,1\}$ and each wins with probability one half. To make the problem non-trivial, in what follows I assume that $C \in(0,1]$.

The following proposition characterizes a political equilibrium in which the parties announce symmetric (around $\frac{1}{2}$ ) platforms and each wins with probability one half. (The proof of this and other propositions can be found in the Appendix.)

Proposition 2. There is a unique political equilibrium with symmetric platforms $\left\{\frac{1-C}{2}, \frac{1+C}{2}\right\}$ when $C \in(0,1), \alpha_{1} \in\left[0, \frac{1-C}{2}\right], \alpha_{2} \in\left[\frac{1+C}{2}, 1\right]$. There is a unique political equilibrium with symmetric platforms $\{0,1\}$ when $C=1, \alpha_{1} \in\left[0, \frac{1}{2}\right), \alpha_{2} \in\left(\frac{1}{2}, 1\right]$.

Therefore, in this equilibrium, when $C \in(0,1)$ the parties announce more moderate platforms than their MPPs $\alpha_{1}$ and $\alpha_{2}$. The announced platforms are symmetric around $\frac{1}{2}$ and at a distance of $C$ from each other. Each party wins with probability one half. The expected payoff for party $i$ is equal to $-\left|\frac{1}{2}-\alpha_{i}\right|-\frac{C}{2}$. No party wants to deviate by announcing a more moderate platform and winning the election. The reason is that the gains in terms of implemented policy (which are less than $\frac{C}{2}$ ) do not compensate the losses in terms of policymaking $\operatorname{cost} \frac{C}{2}$. Neither party gains by announcing a more extreme platform and losing the election. This is because the gains in terms of policy-making cost $\frac{C}{2}$ are equal to the losses in terms of implemented policy. When $C=1$, the parties announce the most extreme platforms $\{0,1\}$. In this case, no party wants to deviate by announcing a less extreme platform and 
winning the election, as the losses in terms of policy-making cost $\frac{C}{2}=\frac{1}{2}$ would exceed the policy gains.

I turn now to the characterization of equilibria in which the parties announce asymmetric platforms and one party wins the election with probability one. The following lemma establishes an important property of political equilibria with asymmetric platforms.

Lemma 1. In an equilibrium with asymmetric platforms, the winning party necessarily announces its MPP.

Proof. This lemma is easily proved by contradiction. Suppose that there is an equilibrium in which the winning party, say $i$, announces a platform $x_{i}^{*} \neq \alpha_{i}$. Party $i$, however, can always profitably deviate to the direction of its ideal policy $\alpha_{i}$ by a small positive number $\varepsilon$ and still win the election. It follows that in an equilibrium with asymmetric platforms, a winning party announces its MPP.

An equilibrium $\left\{x_{1}^{*}, x_{2}^{*}\right\}$ in which the parties announce asymmetric platforms must therefore have one of the two following structures:

1. $\left\{\alpha_{1}, x_{2}^{*}\right\}$ such that $x_{2}^{*}>1-\alpha_{1}$. Party 1 wins the election, i.e., $p\left(\alpha_{1}, x_{2}^{*}\right)=1$.

2. $\left\{x_{1}^{*}, \alpha_{2}\right\}$ such that $x_{1}^{*}<1-\alpha_{2}$. Party 2 wins the election, i.e., $p\left(x_{1}^{*}, \alpha_{2}\right)=0$.

The following proposition characterizes political equilibria with asymmetric platforms.

Proposition 3. There is an equilibrium with asymmetric platforms $\left\{\alpha_{1}, x_{2}^{*}\right\}$ in which party 1 wins the election for the following values of $C, \alpha_{1}, \alpha_{2}$ and $x_{2}^{*}$ :

$$
\begin{array}{llll}
C \in(0,1), & \alpha_{1} \in\left(\max \left\{0, \frac{1-2 C}{2}\right\}, \frac{1-C}{2}\right), & \alpha_{2} \in\left(\frac{1}{2}, \alpha_{1}+C\right], & x_{2}^{*} \in\left(1-\alpha_{1}, 1\right] ; \\
C \in(0,1), & \alpha_{1}=\frac{1-C}{2}, & \alpha_{2} \in\left(\frac{1}{2}, 1\right], & x_{2}^{*} \in\left(1-\alpha_{1}, 1\right] ; \\
C \in(0,1), & \alpha_{1} \in\left(\frac{1-C}{2}, \min \left\{\frac{1}{2}, 1-C\right\}\right), & \alpha_{2} \in\left(\frac{1}{2}, 1\right], & x_{2}^{*} \in\left[\alpha_{1}+C, 1\right] ; \\
C \in(0,1), & \alpha_{1} \in\left[\min \left\{\frac{1}{2}, 1-C\right\}, \frac{1}{2}\right), & \alpha_{2} \in\left(\frac{1}{2}, 1\right], & x_{2}^{*}=1 ; \\
C=1, & \alpha_{1} \in\left(0, \frac{1}{2}\right), & \alpha_{2} \in\left(\frac{1}{2}, 1\right], & x_{2}^{*}=1 .
\end{array}
$$

There is an equilibrium with asymmetric platforms $\left\{x_{1}^{*}, \alpha_{2}\right\}$ in which party 2 wins the election for the following values of $C, \alpha_{1}, \alpha_{2}$ and $x_{1}^{*}$ :

$$
\begin{array}{llll}
C \in(0,1), & \alpha_{2} \in\left(\frac{1}{2}, \max \left\{\frac{1}{2}, C\right\}\right], & \alpha_{1} \in\left[0, \frac{1}{2}\right), & x_{1}^{*}=0 ; \\
C \in(0,1), & \alpha_{2} \in\left(\max \left\{\frac{1}{2}, C\right\}, \frac{1+C}{2}\right), & \alpha_{1} \in\left[0, \frac{1}{2}\right), & x_{1}^{*} \in\left[0, \alpha_{2}-C\right] ; \\
C \in(0,1), & \alpha_{2}=\frac{1+C}{2}, & \alpha_{1} \in\left[0, \frac{1}{2}\right), & x_{1}^{*} \in\left[0,1-\alpha_{2}\right) ; \\
C \in(0,1), & \alpha_{2} \in\left(\frac{1+C}{2}, \min \left\{1, \frac{1+2 C}{2}\right\}\right), & \alpha_{1} \in\left[\alpha_{2}-C, \frac{1}{2}\right), & x_{1}^{*} \in\left[0,1-\alpha_{2}\right) ; \\
C=1, & \alpha_{2} \in\left(\frac{1}{2}, 1\right), & \alpha_{1} \in\left[0, \frac{1}{2}\right), & x_{1}^{*}=0 .
\end{array}
$$


It is important to stress here that in some cases there is a continuum of payoff-equivalent equilibria with asymmetric platforms in which winning party $i$ announces its MPP $\alpha_{i}$ and obtains a payoff of $-C$, while losing party $j$ announces any policy from an equilibrium interval and obtains a payoff of $-\left|\alpha_{j}-\alpha_{i}\right|, i, j=1,2, i \neq j$. I refer to such a continuum of payoff-equivalent equilibria as one equilibrium, specifying that a losing party can choose any platform from an equilibrium interval.

Note that the party problem is symmetric and therefore equilibria with asymmetric platforms are symmetric around $\frac{1}{2}$. In other words, if there is an equilibrium in which party 1 wins the election for the pair of MPPs $\alpha_{1}$ and $\alpha_{2}$, then there is an equilibrium in which party 2 wins the election for the pair of MPPs $1-\alpha_{2}$ and $1-\alpha_{1}$. Consider an equilibrium with asymmetric platforms in which, say, party 1 wins the election, $\left\{\alpha_{1}, x_{2}^{*}\right\}$. (The intuition for an equilibrium in which party 2 wins the election is analogous.) Party 2's announced platform is more extreme than party 1 's, i.e., $x_{2}^{*}>1-\alpha_{1}$. Party 1 implements its MPP and therefore obtains $-C$. It has no incentive to deviate by announcing a more extreme policy and tying or losing the election. In this case, the gains in terms of policy-making $\operatorname{cost}\left(\frac{C}{2}\right.$ if tying or $C$ if losing) do not compensate the losses in terms of implemented policy $\left(x_{2}^{*}-\frac{1}{2}\right.$ if tying or $x_{2}^{*}-\alpha_{1}$ if losing) for $x_{2}^{*}$ specified in Proposition 3. Party 2 loses the election and obtains a payoff of $\alpha_{1}-\alpha_{2}$. It would not deviate by announcing a less extreme policy and tying or winning the election. Indeed, in this case, party 2 would carry a policy-making cost ( $\frac{C}{2}$ if tying or $C$ if winning) that exceeds the gains in terms of implemented policy ( $\min \left\{\alpha_{2}, 1-\alpha_{1}\right\}-\frac{1}{2}$ if tying or $\alpha_{2}-\alpha_{1}$ if winning) for the parameter values specified in Proposition 3.

Figures 3.1 and 3.2 represent political equilibria for $C \in\left(0, \frac{1}{2}\right]$ and $C \in\left(\frac{1}{2}, 1\right)$, respectively. The horizontal axis depicts the MPP of party $1, \alpha_{1} \in\left[0, \frac{1}{2}\right)$, and the vertical axis depicts the MPP of party $2, \alpha_{2} \in\left(\frac{1}{2}, 1\right]$. The dashed lines represent the boundaries of open sets. Figures 3.1 and 3.2 specify how many and what equilibria there are for each pair of party MPPs $\left\{\alpha_{1}, \alpha_{2}\right\} \in\left[0, \frac{1}{2}\right) \times\left(\frac{1}{2}, 1\right]$. Note that if the distance between the party MPPs is greater than the policy-making cost $C$, i.e., $\alpha_{2}-\alpha_{1}>C$, or if one of the parties has an extreme MPP, i.e., $\alpha_{1}=0$ or $\alpha_{2}=1$, then there is just one political equilibrium for $C \in(0,1)$. Otherwise, there are two political equilibria for $C \in(0,1)$. The reason is that when $\alpha_{2}-\alpha_{1}>C$, only the party with the less extreme MPP wins in an equilibrium with asymmetric platforms. If the party with the more extreme MPP wins, this cannot be an equilibrium with asymmetric platforms since the party with the less extreme MPP would like to deviate to win the election. Indeed, the losses in terms of policy-making cost $C$ if winning are less than the gains in terms of implemented policy $\alpha_{2}-\alpha_{1}$. However, when $\alpha_{2}-\alpha_{1} \leq C$, there are two equilibria with asymmetric platforms, since both the party with the less extreme MPP and the party with 


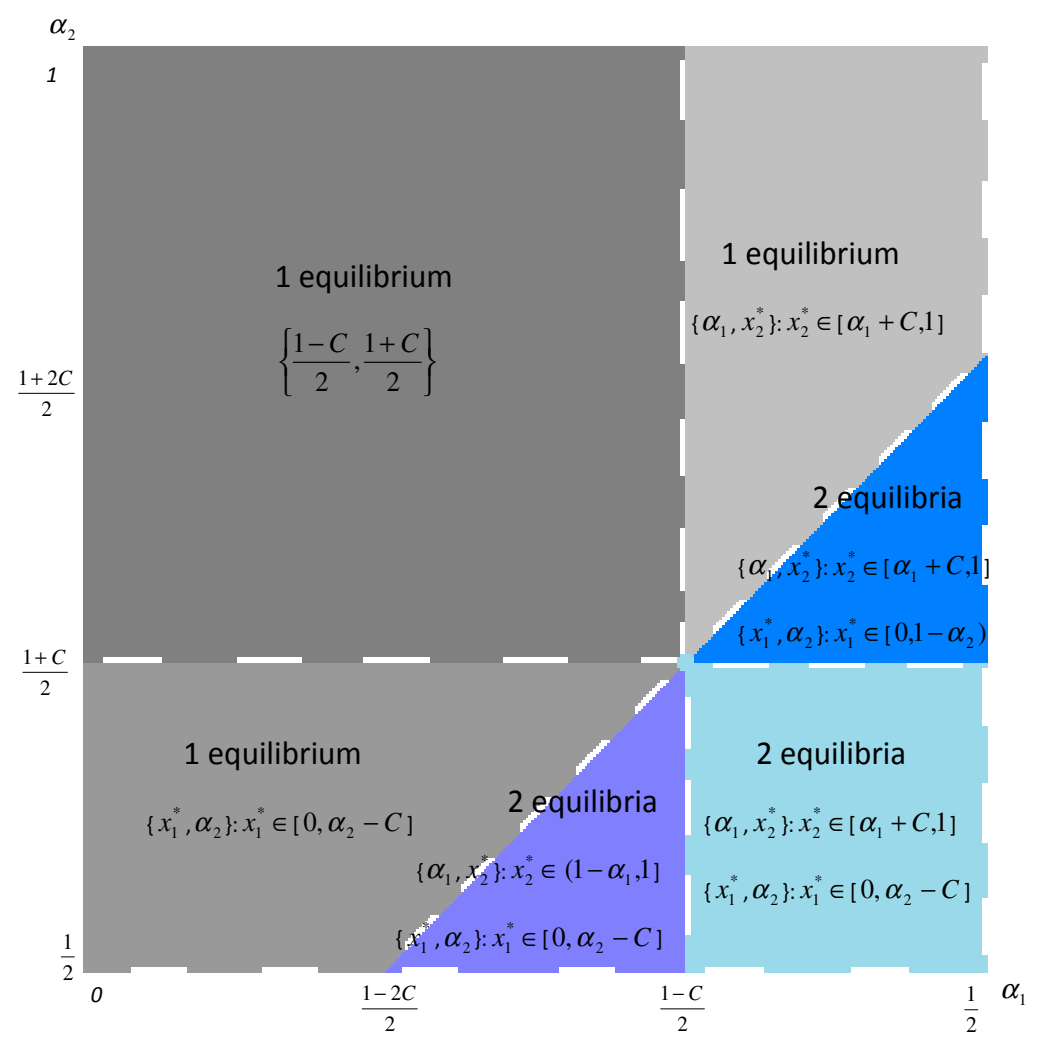

Figure 3.1: Political equilibria for $C \in\left(0, \frac{1}{2}\right]$.

the more extreme MPP can win the election. In an equilibrium in which the party with the more extreme MPP wins, the party with the less extreme MPP does not want to deviate to win the election as the losses in terms of policy-making cost $C$ if winning exceed the gains in terms of implemented policy $\alpha_{2}-\alpha_{1}$. Political equilibria for $C \in(0,1)$ are formally described in Table 1 in the Appendix.

Table 2 in the Appendix describes political equilibria for $C=1$. When $C=1$, there is an equilibrium with extreme symmetric platforms $\{0,1\}$. Moreover, when $C=1$ and the parties are not extreme, i.e., $\alpha_{1} \neq 0$ and $\alpha_{2} \neq 1$, there are two more equilibria with asymmetric platforms $\left\{\alpha_{1}, 1\right\}$ and $\left\{0, \alpha_{2}\right\}$. If one of the parties is extreme, only one equilibrium with asymmetric platforms arises for $C=1:\left\{0, \alpha_{2}\right\}$ when $\alpha_{1}=0$ or $\left\{\alpha_{1}, 1\right\}$ when $\alpha_{2}=1$.

It is important to stress here that I consider two well-established parties that would not exit political competition. The model predictions would change if the parties made decisions regarding entry. However, I want to concentrate the analysis on a two-party system with policy-motivated parties that will definitely run for office. The following theorem summarizes 


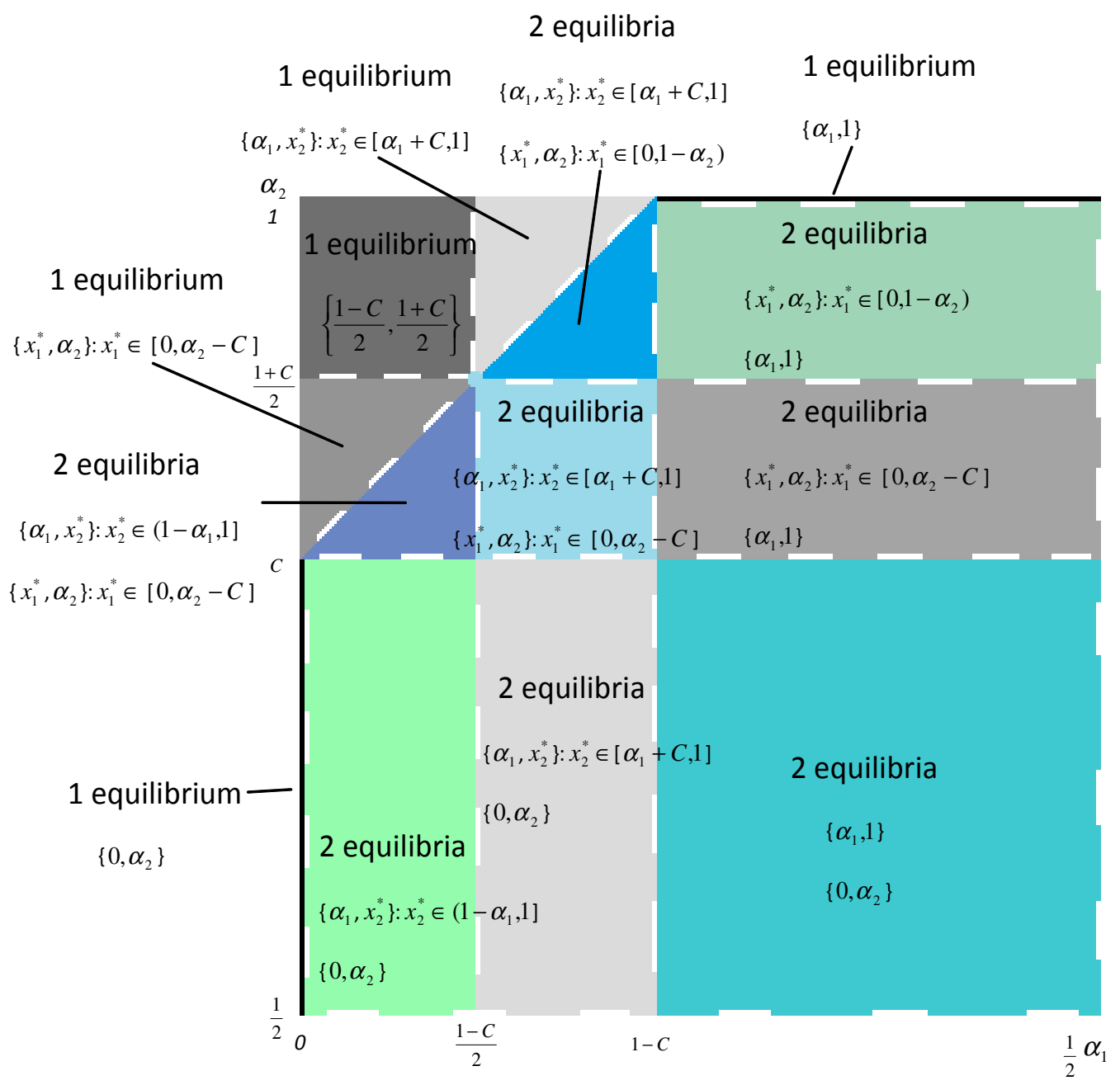

Figure 3.2: Political equilibria for $C \in\left(\frac{1}{2}, 1\right)$.

the above results.

Theorem 3.1. i) When the policy-making cost exceeds the length of the set of feasible policies $(C>1)$, there is a unique equilibrium in which the parties announce the most extreme policies $\{0,1\}$ and each party wins with probability one half.

ii) When the policy-making cost equals the length of the set of feasible policies $(C=1)$, there is an equilibrium with extreme symmetric platforms $\{0,1\}$ for any $\alpha_{1} \in\left[0, \frac{1}{2}\right)$ and $\alpha_{2} \in\left(\frac{1}{2}, 1\right]$. Moreover, there are two equilibria with asymmetric platforms $\left\{\alpha_{1}, 1\right\}$ and $\left\{0, \alpha_{2}\right\}$ when the party MPPs are not extreme, i.e., when $\alpha_{1} \in\left(0, \frac{1}{2}\right)$ and $\alpha_{2} \in\left(\frac{1}{2}, 1\right)$. If party 1 is extreme $\left(\alpha_{1}=0\right)$, there is an equilibrium $\left\{0, \alpha_{2}\right\}$. If party 2 is extreme 
$\left(\alpha_{2}=1\right)$, there is an equilibrium $\left\{\alpha_{1}, 1\right\}$.

iii) When the policy-making cost is lower than the length of the set of feasible policies $(C<1)$, depending on the party MPPs there are either one or two political equilibria. If the distance between the party MPPs does not exceed the policy-making cost $\left(\alpha_{2}-\alpha_{1} \leq C\right)$ and the parties are not extreme $\left(\alpha_{1} \neq 0\right.$ and $\left.\alpha_{2} \neq 1\right)$, then there are two equilibria with asymmetric platforms whereby the winning party announces its MPP and the losing party announces any policy from a certain equilibrium interval. Otherwise, there is a unique political equilibrium: if $\alpha_{1} \in\left[0, \frac{1-C}{2}\right]$ and $\alpha_{2} \in\left[\frac{1+C}{2}, 1\right]$ this is an equilibrium with symmetric platforms $\left\{\frac{1-C}{2}, \frac{1+C}{2}\right\}$; otherwise, this is an equilibrium with asymmetric platforms in which the party with the less extreme MPP announces its MPP and wins the election and the losing party announces any policy from a certain equilibrium interval.

A welfare analysis of the problem is of interest. I define social welfare as the aggregate welfare of society excluding the party payoffs. ${ }^{3}$ Therefore, when the implemented policy is $x$, social welfare, denoted by $W(\cdot)$, is equal to:

$$
W(x)=\int_{0}^{1}-|x-y| d y=-\frac{1}{2}+x-x^{2},
$$

which is symmetric around $\frac{1}{2}$ and takes a maximum in $\frac{1}{2}$. It follows then that the closer the implemented policy is to $\frac{1}{2}$, the better off is society. Thus, in the cases of two equilibria with asymmetric platforms $\left\{\alpha_{1}, x_{2}^{*}\right\}$ and $\left\{x_{1}^{*}, \alpha_{2}\right\}$, they can be ranked according to the social welfare they generate: $W\left(\alpha_{1}\right) \gtreqless W\left(\alpha_{2}\right)$ if $\alpha_{1} \gtreqless 1-\alpha_{2}$. The same predictions are achieved if the party payoffs $-C$ and $-\left(\alpha_{2}-\alpha_{1}\right)$ are included in the social welfare function.

\section{Conclusion}

This paper builds a simple model of political competition in a two-party system under the assumption of costly policy-making in hard times of crisis. Two policy-motivated parties simultaneously announce policy platforms under complete information, full commitment and zero abstention. Hard times are modeled in terms of a fixed policy-making cost, which a winning party carries once in office. I characterize political equilibria of the game for different policy-making costs and party MPPs. An important feature of political competition in hard times is the non-existence of equilibrium with policy convergence. For moderate

\footnotetext{
${ }^{3}$ Alternatively, the party payoffs could be introduced in the social welfare function.
} 
policy-making costs there are either one or two political equilibria. If the distance between party MPPs does not exceed the policy-making cost, there are two equilibria with asymmetric platforms in which the winning party announces its MPP. Otherwise, there is a unique political equilibrium. When the parties are quite extreme, then an equilibrium with symmetric platforms occurs in which each party wins with probability one half. If one party is extreme and the other party is relatively more moderate, this is an equilibrium with asymmetric platforms in which the party with the more moderate MPP announces it as a platform and wins the election. For high policy-making costs there is a unique equilibrium in which the parties announce the most extreme policies and each wins with probability one half.

Even though the model is very stylized, it yields a number of empirically testable predictions. Policy-making is definitely more costly in hard times than in good times. In fact, in good times the policy-making cost might be zero or negative, reflecting the ego rents of the parties from policy-making. A standard model of political competition with two policymotivated parties and ego rents predicts policy convergence to the preferred policy of the median voter (Wittman 1990, Calvert 1985). My model of political competition under costly policy-making emphasizes the non-existence of political equilibrium with policy convergence. It predicts not only policy divergence, but also equilibria in which the parties announce asymmetric platforms. Therefore, simple testable hypotheses might be as follows. First, in a two-party system, the parties announce more convergent platforms in boom times and less convergent platforms in recession times. Second, the winning margin is expected to be greater during a recession than during a boom.

Note that I have focused on political competition with an exogenous policy-making cost. It would be of interest to consider a setting in which such a cost arises endogenously. The model can also be generalized by considering a non-symmetric distribution of voter MPPs. These tasks are left for future research.

\section{Appendix}

\section{A. Proof of Proposition 2}

Consider a pair of policy proposals $\left\{x_{1}, x_{2}\right\}$ such that $x_{1}=1-x_{2}, x_{1} \in\left(0, \frac{1}{2}\right), x_{2} \in\left(\frac{1}{2}, 1\right)$. Given these $x_{1}$ and $x_{2}$, each party wins with probability one-half. Party 1's payoff is equal to $\Pi_{1}\left(x_{1}, x_{2}\right)=\frac{1}{2}\left(-\left|x_{1}-\alpha_{1}\right|-C\right)+\frac{1}{2}\left(-\left|x_{2}-\alpha_{1}\right|\right)$. Party 2 's payoff is equal to $\Pi_{2}\left(x_{1}, x_{2}\right)=$ $\frac{1}{2}\left(-\left|x_{1}-\alpha_{2}\right|\right)+\frac{1}{2}\left(-\left|x_{2}-\alpha_{2}\right|-C\right)$. 
1. If party 1 deviates and announces a platform $x_{1}^{\prime} \in\left[0, x_{1}\right)$, then it loses the election and gets the payoff $\Pi_{1}\left(x_{1}^{\prime}, x_{2}\right)=-\left|x_{2}-\alpha_{1}\right|$. Such a deviation is not profitable only if $\Pi_{1}\left(x_{1}, x_{2}\right) \geq \Pi_{1}\left(x_{1}^{\prime}, x_{2}\right)$, which yields $-\left|x_{1}-\alpha_{1}\right|-C \geq-\left(1-x_{1}-\alpha_{1}\right)$. If party 1 deviates and announces a platform $x_{1}^{\prime \prime} \in\left(x_{1}, \frac{1}{2}\right]$, then it wins the election and gets the payoff $\Pi_{1}\left(x_{1}^{\prime \prime}, x_{2}\right)=-\left|x_{1}^{\prime \prime}-\alpha_{1}\right|-C$. Such a deviation is not profitable only if $\Pi_{1}\left(x_{1}, x_{2}\right) \geq$ $\Pi_{1}\left(x_{1}^{\prime \prime}, x_{2}\right)$, which implies $\frac{1}{2}\left(-\left|x_{1}-\alpha_{1}\right|-C\right)+\frac{1}{2}\left(-1+x_{1}+\alpha_{1}\right) \geq-\left|x_{1}^{\prime \prime}-\alpha_{1}\right|-C$.

a) Consider the case where $x_{1}<\alpha_{1}$. The conditions $\Pi_{1}\left(x_{1}, x_{2}\right) \geq \Pi_{1}\left(x_{1}^{\prime}, x_{2}\right)$ and $\Pi_{1}\left(x_{1}, x_{2}\right) \geq \Pi_{1}\left(x_{1}^{\prime \prime}, x_{2}\right)$ become $\alpha_{1} \leq \frac{1-C}{2}$ and $x_{1} \geq \frac{1-C}{2}-\left|x_{1}^{\prime \prime}-\alpha_{1}\right|$, respectively. To guarantee that the latter inequality holds for each $x_{1}^{\prime \prime} \in\left(x_{1}, \frac{1}{2}\right]$, it is required that $x_{1} \geq \frac{1-C}{2}$. It follows then that $\alpha_{1} \leq \frac{1-C}{2} \leq x_{1}$, which does not hold for $x_{1}<\alpha_{1}$. Therefore, when $x_{1}<\alpha_{1}$, party 1 can deviate profitably.

b) Consider the case where $x_{1} \geq \alpha_{1}$. The conditions $\Pi_{1}\left(x_{1}, x_{2}\right) \geq \Pi_{1}\left(x_{1}^{\prime}, x_{2}\right)$ and $\Pi_{1}\left(x_{1}, x_{2}\right) \geq \Pi_{1}\left(x_{1}^{\prime \prime}, x_{2}\right)$ become $x_{1} \leq \frac{1-C}{2}$ and $x_{1}^{\prime \prime} \geq \frac{1-C}{2}$, respectively. The latter inequality holds for each $x_{1}^{\prime \prime} \in\left(x_{1}, \frac{1}{2}\right]$ only if $x_{1}=\frac{1-C}{2}$ (where $C<1$ ). Indeed, if $x_{1}<\frac{1-C}{2}$ then there is $x_{1}^{\prime \prime} \in\left(x_{1}, \frac{1-C}{2}\right)$ that implies that party 1 has a profitable deviation. Therefore, party 1 will not deviate only if $\alpha_{1} \leq \frac{1-C}{2}$ and $x_{1}=\frac{1-C}{2}$, where $C<1$.

2. If party 2 deviates and announces a platform $x_{2}^{\prime} \in\left(x_{2}, 1\right]$, then it loses the election and gets the payoff $\Pi_{2}\left(x_{1}, x_{2}^{\prime}\right)=-\left|x_{1}-\alpha_{2}\right|$. Such a deviation is not profitable only if $\Pi_{2}\left(x_{1}, x_{2}\right) \geq \Pi_{2}\left(x_{1}, x_{2}^{\prime}\right)$, which implies $-\left|x_{2}-\alpha_{2}\right|-C \geq 1-x_{2}-\alpha_{2}$. If party 2 deviates and announces a platform $x_{2}^{\prime \prime} \in\left[\frac{1}{2}, x_{2}\right)$, then it wins the election and its payoff becomes $\Pi_{2}\left(x_{1}, x_{2}^{\prime \prime}\right)=-\left|x_{2}^{\prime \prime}-\alpha_{2}\right|-C$. This deviation is not profitable only if $\Pi_{2}\left(x_{1}, x_{2}\right) \geq$ $\Pi_{2}\left(x_{1}, x_{2}^{\prime \prime}\right)$, which yields $\frac{1}{2}\left(1-x_{2}-\alpha_{2}\right)+\frac{1}{2}\left(-\left|x_{2}-\alpha_{2}\right|-C\right) \geq-\left|x_{2}^{\prime \prime}-\alpha_{2}\right|-C$.

a) Consider the case where $x_{2}>\alpha_{2}$. The conditions $\Pi_{2}\left(x_{1}, x_{2}\right) \geq \Pi_{2}\left(x_{1}, x_{2}^{\prime}\right)$ and $\Pi_{2}\left(x_{1}, x_{2}\right) \geq \Pi_{2}\left(x_{1}, x_{2}^{\prime \prime}\right)$ become $\alpha_{2} \geq \frac{1+C}{2}$ and $x_{2} \leq \frac{1+C}{2}+\left|x_{2}^{\prime \prime}-\alpha_{2}\right|$, respectively. To guarantee that the latter inequality holds for each $x_{2}^{\prime \prime} \in\left[\frac{1}{2}, x_{2}\right)$, it is necessary that $x_{2} \leq \frac{1+C}{2}$. Therefore, $x_{2} \leq \frac{1+C}{2} \leq \alpha_{2}$, which is not possible for $x_{2}>\alpha_{2}$. Therefore, party 2 has profitable deviations when $x_{2}>\alpha_{2}$.

b) Consider the case where $x_{2} \leq \alpha_{2}$. The conditions $\Pi_{2}\left(x_{1}, x_{2}\right) \geq \Pi_{2}\left(x_{1}, x_{2}^{\prime}\right)$ and $\Pi_{2}\left(x_{1}, x_{2}\right) \geq \Pi_{2}\left(x_{1}, x_{2}^{\prime \prime}\right)$ become $x_{2} \geq \frac{1+C}{2}$ and $x_{2}^{\prime \prime} \leq \frac{1+C}{2}$, respectively. The latter inequality holds for each $x_{2}^{\prime \prime} \in\left[\frac{1}{2}, x_{2}\right)$ only if $x_{2}=\frac{1+C}{2}$ (where $C<1$ ). Indeed, if $x_{2}>\frac{1+C}{2}$ then there is $x_{2}^{\prime \prime} \in\left(\frac{1+C}{2}, x_{2}\right)$ that means that party 2 has a profitable 
deviation. Thus, party 2 will not deviate only if $\alpha_{2} \geq \frac{1+C}{2}$ and $x_{2}=\frac{1+C}{2}$, where $C<1$.

Therefore, both parties do not deviate from $\left\{x_{1}, x_{2}\right\}$ such that $x_{1}=1-x_{2}, x_{1} \in\left(0, \frac{1}{2}\right)$, $x_{2} \in\left(\frac{1}{2}, 1\right)$ only if $\alpha_{1} \leq \frac{1-C}{2}, \alpha_{2} \geq \frac{1+C}{2}$, and $x_{1}=\frac{1-C}{2}, x_{2}=\frac{1+C}{2}$, where $C<1$. In other words, there is a unique political equilibrium with symmetric platforms $\left\{\frac{1-C}{2}, \frac{1+C}{2}\right\}$ when $\alpha_{1} \leq \frac{1-C}{2}, \alpha_{2} \geq \frac{1+C}{2}, C<1$.

Consider now a pair of policy proposals $\{0,1\}$. Each party wins with probability one-half. The parties' payoffs are equal to $\Pi_{i}(0,1)=-\frac{1}{2}-\frac{C}{2}, i=1,2$. If party $i$ deviates and announces a less extreme policy $x_{i}^{\prime}$, it wins the election and gets the payoff $\Pi_{i}\left(x_{i}^{\prime}, \cdot\right)=-\left|x_{i}^{\prime}-\alpha_{i}\right|-C$. Note that $\Pi_{i}\left(x_{i}^{\prime}, \cdot\right)$ takes its maximum value $-C$ when $x_{i}^{\prime}=\alpha_{i}$. To guarantee that party $i$ has no profitable deviations it is required $\Pi_{i}(0,1) \geq \max \Pi_{i}\left(x_{i}^{\prime}, \cdot\right)$, which amounts to $C \geq 1$. Therefore, $\{0,1\}$ is a political equilibrium for $C \geq 1$.

\section{B. Proof of Proposition 3}

\section{Characterization of an equilibrium in which the parties announce asymmetric platforms and party 1 wins the election.}

Consider a pair of policy proposals $\left\{\alpha_{1}, x_{2}^{*}\right\}$ such that $\alpha_{1} \in\left(0, \frac{1}{2}\right)$ and $x_{2}^{*} \in\left(1-\alpha_{1}, 1\right]$. Given these proposals, party 1 wins the election and gets the payoff $\Pi_{1}\left(\alpha_{1}, x_{2}^{*}\right)=-C$. The payoff of party 2 is equal to $\Pi_{2}\left(\alpha_{1}, x_{2}^{*}\right)=-\left|\alpha_{1}-\alpha_{2}\right|$.

1. If party 1 deviates and announces a platform $x_{1}^{\prime} \in\left(1-x_{2}^{*}, \frac{1}{2}\right]$, then it still wins the election and its payoff becomes $\Pi_{1}\left(x_{1}^{\prime}, x_{2}^{*}\right)=-\left|x_{1}^{\prime}-\alpha_{1}\right|-C$. However, $\Pi_{1}\left(x_{1}^{\prime}, x_{2}^{*}\right)<$ $\Pi_{1}\left(\alpha_{1}, x_{2}^{*}\right)$ and so such a deviation is not profitable. If party 1 deviates and announces a platform $1-x_{2}^{*}$, then there is a tie and each party wins with probability one-half. Party 1 's payoff becomes $\Pi_{1}\left(1-x_{2}^{*}, x_{2}^{*}\right)=\frac{1}{2}\left(-\left|1-x_{2}^{*}-\alpha_{1}\right|-C\right)+\frac{1}{2}\left(-\left|x_{2}^{*}-\alpha_{1}\right|\right)$. Such a deviation is not profitable only if $\Pi_{1}\left(\alpha_{1}, x_{2}^{*}\right) \geq \Pi_{1}\left(1-x_{2}^{*}, x_{2}^{*}\right)$, which implies $x_{2}^{*} \geq \frac{1+C}{2}$, where $C \leq 1$. Consider the case where $x_{2}^{*} \neq 1$. If party 1 deviates and announces $x_{1}^{\prime \prime} \in\left[0,1-x_{2}^{*}\right)$, then it loses the election and gets the payoff $\Pi_{1}\left(x_{1}^{\prime \prime}, x_{2}^{*}\right)=-\left|x_{2}^{*}-\alpha_{1}\right|$. Such a deviation is not profitable only if $\Pi_{1}\left(\alpha_{1}, x_{2}^{*}\right) \geq \Pi_{1}\left(x_{1}^{\prime \prime}, x_{2}^{*}\right)$, which yields $x_{2}^{*} \geq$ $\alpha_{1}+C$. Therefore, when the parties announce $\left\{\alpha_{1}, x_{2}^{*}\right\}$ such that $\alpha_{1} \in\left(0, \frac{1}{2}\right)$ and $x_{2}^{*} \in\left(1-\alpha_{1}, 1\right)$, party 1 has no profitable deviations only if $x_{2}^{*} \geq \max \left\{\frac{1+C}{2}, \alpha_{1}+C\right\}$, where $C<1$. When the parties announce $\left\{\alpha_{1}, 1\right\}$ such that $\alpha_{1} \in\left(0, \frac{1}{2}\right)$, party 1 has no profitable deviations only if $C \leq 1$. 
2. If party 2 deviates and announces $1-\alpha_{1}$, then there is a tie and each party wins with probability one-half. The payoff of party 2 becomes $\Pi_{2}\left(\alpha_{1}, 1-\alpha_{1}\right)=\frac{1}{2}\left(-\left|\alpha_{1}-\alpha_{2}\right|\right)+$ $\frac{1}{2}\left(-\left|1-\alpha_{1}-\alpha_{2}\right|-C\right)$. Such a deviation is not profitable only if $\Pi_{2}\left(\alpha_{1}, x_{2}^{*}\right) \geq \Pi_{2}\left(\alpha_{1}, 1-\alpha_{1}\right)$, which amounts to $\alpha_{1}-\alpha_{2} \geq-\left|1-\alpha_{1}-\alpha_{2}\right|-C$. If party 2 deviates and announces $x_{2}^{\prime} \in$ $\left[\frac{1}{2}, 1-\alpha_{1}\right)$, then it wins the election and gets the payoff $\Pi_{2}\left(\alpha_{1}, x_{2}^{\prime}\right)=-\left|x_{2}^{\prime}-\alpha_{2}\right|-C$. This deviation is not profitable only if $\Pi_{2}\left(\alpha_{1}, x_{2}^{*}\right) \geq \Pi_{2}\left(\alpha_{1}, x_{2}^{\prime}\right)$, which implies $\alpha_{1}-\alpha_{2} \geq$ $-\left|x_{2}^{\prime}-\alpha_{2}\right|-C$.

a) Consider the case where $\alpha_{2}<1-\alpha_{1}$. The conditions $\Pi_{2}\left(\alpha_{1}, x_{2}^{*}\right) \geq \Pi_{2}\left(\alpha_{1}, 1-\alpha_{1}\right)$ and $\Pi_{2}\left(\alpha_{1}, x_{2}^{*}\right) \geq \Pi_{2}\left(\alpha_{1}, x_{2}^{\prime}\right)$ become $\alpha_{2} \leq \frac{1+C}{2}$ and $\alpha_{2} \leq \alpha_{1}+C$, respectively. It implies therefore that in case $\alpha_{2}<1-\alpha_{1}$, party 2 will not deviate only if $\alpha_{2} \leq \min \left\{\frac{1+C}{2}, \alpha_{1}+C\right\}$.

b) Consider the case where $\alpha_{2}=1-\alpha_{1}$. The conditions $\Pi_{2}\left(\alpha_{1}, x_{2}^{*}\right) \geq \Pi_{2}\left(\alpha_{1}, 1-\alpha_{1}\right)$ and $\Pi_{2}\left(\alpha_{1}, x_{2}^{*}\right) \geq \Pi_{2}\left(\alpha_{1}, x_{2}^{\prime}\right)$ become $\alpha_{2} \leq \alpha_{1}+C$ and $x_{2}^{\prime} \leq \alpha_{1}+C$, respectively. Once the former inequality holds, the latter inequality will hold too since $x_{2}^{\prime}<$ $1-\alpha_{1}=\alpha_{2} \leq \alpha_{1}+C$. It means that in case $\alpha_{2}=1-\alpha_{1}$, party 2 will not deviate only if $\alpha_{2} \leq \alpha_{1}+C$, which amounts to $\alpha_{1} \geq \frac{1-C}{2}$.

c) Consider the case where $\alpha_{2}>1-\alpha_{1}$. The conditions $\Pi_{2}\left(\alpha_{1}, x_{2}^{*}\right) \geq \Pi_{2}\left(\alpha_{1}, 1-\alpha_{1}\right)$ and $\Pi_{2}\left(\alpha_{1}, x_{2}^{*}\right) \geq \Pi_{2}\left(\alpha_{1}, x_{2}^{\prime}\right)$ become $\alpha_{1} \geq \frac{1-C}{2}$ and $x_{2}^{\prime} \leq \alpha_{1}+C$, respectively. Once the former inequality holds, the latter inequality will hold too since the former inequality implies $1-\alpha_{1} \leq \alpha_{1}+C$, and therefore $x_{2}^{\prime}<1-\alpha_{1} \leq \alpha_{1}+C$. It follows then that in case $\alpha_{2}>1-\alpha_{1}$, party 2 has no profitable deviations only if $\alpha_{1} \geq \frac{1-C}{2}$.

Therefore, when the parties announce $\left\{\alpha_{1}, x_{2}^{*}\right\}$ such that $\alpha_{1} \in\left(0, \frac{1}{2}\right)$ and $x_{2}^{*} \in\left(1-\alpha_{1}, 1\right]$, party 2 has no profitable deviations only in the following cases: either $\alpha_{2}<1-\alpha_{1}$ and $\alpha_{2} \leq \min \left\{\frac{1+C}{2}, \alpha_{1}+C\right\}$ or $\alpha_{2} \geq 1-\alpha_{1}$ and $\alpha_{1} \geq \frac{1-C}{2}$.

Combining the conditions that guarantee that neither party has profitable deviations yields the set of the parameters for which there is an equilibrium with asymmetric platforms $\left\{\alpha_{1}, x_{2}^{*}\right\}$ with party 1 winning:

$$
\begin{array}{llll}
C \in(0,1), & \alpha_{1} \in\left(\max \left\{0, \frac{1-2 C}{2}\right\}, \frac{1-C}{2}\right), & \alpha_{2} \in\left(\frac{1}{2}, \alpha_{1}+C\right], & x_{2}^{*} \in\left(1-\alpha_{1}, 1\right] ; \\
C \in(0,1), & \alpha_{1}=\frac{1-C}{2}, & \alpha_{2} \in\left(\frac{1}{2}, 1\right], & x_{2}^{*} \in\left(1-\alpha_{1}, 1\right] ; \\
C \in(0,1), & \alpha_{1} \in\left(\frac{1-C}{2}, \min \left\{\frac{1}{2}, 1-C\right\}\right), & \alpha_{2} \in\left(\frac{1}{2}, 1\right], & x_{2}^{*} \in\left[\alpha_{1}+C, 1\right] ; \\
C \in(0,1), & \alpha_{1} \in\left[\min \left\{\frac{1}{2}, 1-C\right\}, \frac{1}{2}\right), & \alpha_{2} \in\left(\frac{1}{2}, 1\right], & x_{2}^{*}=1 ; \\
C=1, & \alpha_{1} \in\left(0, \frac{1}{2}\right), & \alpha_{2} \in\left(\frac{1}{2}, 1\right], & x_{2}^{*}=1 .
\end{array}
$$




\section{Characterization of an equilibrium in which the parties announce asymmetric platforms and party 2 wins the election.}

Consider a pair of policy proposals $\left\{x_{1}^{*}, \alpha_{2}\right\}$ such that $\alpha_{2} \in\left(\frac{1}{2}, 1\right)$ and $x_{1}^{*} \in\left[0,1-\alpha_{2}\right)$. Given these proposals, party 2 wins the election and gets the payoff $\Pi_{2}\left(x_{1}^{*}, \alpha_{2}\right)=-C$. The payoff of party 1 is equal to $\Pi_{1}\left(x_{1}^{*}, \alpha_{2}\right)=-\left|\alpha_{2}-\alpha_{1}\right|$.

1. If party 2 deviates and announces a platform $x_{2}^{\prime} \in\left[\frac{1}{2}, 1-x_{1}^{*}\right)$, then it still wins the election and its payoff becomes $\Pi_{2}\left(x_{1}^{*}, x_{2}^{\prime}\right)=-\left|x_{2}^{\prime}-\alpha_{2}\right|-C$. However, $\Pi_{2}\left(x_{1}^{*}, x_{2}^{\prime}\right)<$ $\Pi_{2}\left(x_{1}^{*}, \alpha_{2}\right)$ and so such a deviation is not profitable. If party 2 deviates and announces a platform $1-x_{1}^{*}$, then there is a tie and each party wins with probability one-half. Party 2 's payoff becomes $\Pi_{2}\left(x_{1}^{*}, 1-x_{1}^{*}\right)=\frac{1}{2}\left(-\left|x_{1}^{*}-\alpha_{2}\right|\right)+\frac{1}{2}\left(-\left|1-x_{1}^{*}-\alpha_{2}\right|-C\right)$. Such a deviation is not profitable only if $\Pi_{2}\left(x_{1}^{*}, \alpha_{2}\right) \geq \Pi_{2}\left(x_{1}^{*}, 1-x_{1}^{*}\right)$, which implies $x_{1}^{*} \leq \frac{1-C}{2}$, where $C \leq 1$. Consider the case where $x_{1}^{*} \neq 0$. If party 2 deviates and announces $x_{2}^{\prime \prime} \in\left(1-x_{1}^{*}, 1\right]$, then it loses the election and gets the payoff $\Pi_{2}\left(x_{1}^{*}, x_{2}^{\prime \prime}\right)=-\left|x_{1}^{*}-\alpha_{2}\right|$. Such a deviation is not profitable only if $\Pi_{2}\left(x_{1}^{*}, \alpha_{2}\right) \geq \Pi_{2}\left(x_{1}^{*}, x_{2}^{\prime \prime}\right)$, which yields $x_{1}^{*} \leq$ $\alpha_{2}-C$. Therefore, when the parties announce $\left\{x_{1}^{*}, \alpha_{2}\right\}$ such that $\alpha_{2} \in\left(\frac{1}{2}, 1\right)$ and $x_{1}^{*} \in\left(0,1-\alpha_{2}\right)$, party 2 has no profitable deviations only if $x_{1}^{*} \leq \min \left\{\frac{1-C}{2}, \alpha_{2}-C\right\}$, where $C<1$. When the parties announce $\left\{0, \alpha_{2}\right\}$ such that $\alpha_{2} \in\left(\frac{1}{2}, 1\right)$, party 2 has no profitable deviations only if $C \leq 1$.

2. If party 1 deviates and announces $1-\alpha_{2}$, then there is a tie and each party wins with probability one-half. The payoff of party 1 becomes $\Pi_{1}\left(1-\alpha_{2}, \alpha_{2}\right)=\frac{1}{2}\left(-\left|1-\alpha_{2}-\alpha_{1}\right|-C\right)+$ $\frac{1}{2}\left(-\left|\alpha_{2}-\alpha_{1}\right|\right)$. Such a deviation is not profitable only if $\Pi_{1}\left(x_{1}^{*}, \alpha_{2}\right) \geq \Pi_{1}\left(1-\alpha_{2}, \alpha_{2}\right)$, which amounts to $\alpha_{1}-\alpha_{2} \geq-\left|1-\alpha_{2}-\alpha_{1}\right|-C$. If party 1 deviates and announces $x_{1}^{\prime} \in$ $\left(1-\alpha_{2}, \frac{1}{2}\right]$, then it wins the election and gets the payoff $\Pi_{1}\left(x_{1}^{\prime}, \alpha_{2}\right)=-\left|x_{1}^{\prime}-\alpha_{1}\right|-C$. This deviation is not profitable only if $\Pi_{1}\left(x_{1}^{*}, \alpha_{2}\right) \geq \Pi_{1}\left(x_{1}^{\prime}, \alpha_{2}\right)$, which implies $\alpha_{1}-\alpha_{2} \geq$ $-\left|x_{1}^{\prime}-\alpha_{1}\right|-C$.

a) Consider the case where $\alpha_{1}>1-\alpha_{2}$. The conditions $\Pi_{1}\left(x_{1}^{*}, \alpha_{2}\right) \geq \Pi_{1}\left(1-\alpha_{2}, \alpha_{2}\right)$ and $\Pi_{1}\left(x_{1}^{*}, \alpha_{2}\right) \geq \Pi_{1}\left(x_{1}^{\prime}, \alpha_{2}\right)$ become $\alpha_{1} \geq \frac{1-C}{2}$ and $\alpha_{1} \geq \alpha_{2}-C$, respectively. It implies therefore that in case $\alpha_{1}>1-\alpha_{2}$, party 1 will not deviate only if $\alpha_{1} \geq \max \left\{\frac{1-C}{2}, \alpha_{2}-C\right\}$.

b) Consider the case where $\alpha_{1}=1-\alpha_{2}$. The conditions $\Pi_{1}\left(x_{1}^{*}, \alpha_{2}\right) \geq \Pi_{1}\left(1-\alpha_{2}, \alpha_{2}\right)$ and $\Pi_{1}\left(x_{1}^{*}, \alpha_{2}\right) \geq \Pi_{1}\left(x_{1}^{\prime}, \alpha_{2}\right)$ become $\alpha_{1} \geq \alpha_{2}-C$ and $x_{1}^{\prime} \geq \alpha_{2}-C$, respectively. Once the former inequality holds, the latter inequality will hold too since $x_{1}^{\prime}>$ 
$1-\alpha_{2}=\alpha_{1} \geq \alpha_{2}-C$. It means that in case $\alpha_{1}=1-\alpha_{2}$, party 1 will not deviate only if $\alpha_{1} \geq \alpha_{2}-C$, which amounts to $\alpha_{2} \leq \frac{1+C}{2}$.

c) Consider the case where $\alpha_{1}<1-\alpha_{2}$. The conditions $\Pi_{1}\left(x_{1}^{*}, \alpha_{2}\right) \geq \Pi_{1}\left(1-\alpha_{2}, \alpha_{2}\right)$ and $\Pi_{1}\left(x_{1}^{*}, \alpha_{2}\right) \geq \Pi_{1}\left(x_{1}^{\prime}, \alpha_{2}\right)$ become $\alpha_{2} \leq \frac{1+C}{2}$ and $x_{1}^{\prime} \geq \alpha_{2}-C$, respectively. Once the former inequality holds, the latter inequality will hold too since the former inequality implies $1-\alpha_{2} \geq \alpha_{2}-C$, and therefore $x_{1}^{\prime}>1-\alpha_{2} \geq \alpha_{2}-C$. It follows then that in case $\alpha_{1}<1-\alpha_{2}$, party 1 has no profitable deviations only if $\alpha_{2} \leq \frac{1+C}{2}$.

Therefore, when the parties announce $\left\{x_{1}^{*}, \alpha_{2}\right\}$ such that $\alpha_{2} \in\left(\frac{1}{2}, 1\right)$ and $x_{1}^{*} \in\left[0,1-\alpha_{2}\right)$, party 1 has no profitable deviations only in the following cases: either $\alpha_{1}>1-\alpha_{2}$ and $\alpha_{1} \geq \max \left\{\frac{1-C}{2}, \alpha_{2}-C\right\}$ or $\alpha_{1} \leq 1-\alpha_{2}$ and $\alpha_{2} \leq \frac{1+C}{2}$.

Combining the conditions that guarantee that neither party has profitable deviations yields the set of the parameters for which there is an equilibrium with asymmetric platforms $\left\{x_{1}^{*}, \alpha_{2}\right\}$ with party 2 winning:

$$
\begin{array}{llll}
C \in(0,1), & \alpha_{2} \in\left(\frac{1}{2}, \max \left\{\frac{1}{2}, C\right\}\right], & \alpha_{1} \in\left[0, \frac{1}{2}\right), & x_{1}^{*}=0 ; \\
C \in(0,1), & \alpha_{2} \in\left(\max \left\{\frac{1}{2}, C\right\}, \frac{1+C}{2}\right), & \alpha_{1} \in\left[0, \frac{1}{2}\right), & x_{1}^{*} \in\left[0, \alpha_{2}-C\right] ; \\
C \in(0,1), & \alpha_{2}=\frac{1+C}{2}, & \alpha_{1} \in\left[0, \frac{1}{2}\right), & x_{1}^{*} \in\left[0,1-\alpha_{2}\right) ; \\
C \in(0,1), & \alpha_{2} \in\left(\frac{1+C}{2}, \min \left\{1, \frac{1+2 C}{2}\right\}\right), & \alpha_{1} \in\left[\alpha_{2}-C, \frac{1}{2}\right), & x_{1}^{*} \in\left[0,1-\alpha_{2}\right) ; \\
C=1, & \alpha_{2} \in\left(\frac{1}{2}, 1\right), & \alpha_{1} \in\left[0, \frac{1}{2}\right), & x_{1}^{*}=0 .
\end{array}
$$




\begin{tabular}{ll} 
Values of the parameters $C, \alpha_{1}$ and $\alpha_{2}:$ & 1 equilibrium: \\
\hline \hline$C \in(0,1), \alpha_{1} \in\left[0, \frac{1-C}{2}\right), \alpha_{2} \in\left(\frac{1+C}{2}, 1\right]$ & $\left\{\frac{1-C}{2}, \frac{1+C}{2}\right\} ;$ \\
\hline$C \in(0,1), \alpha_{2} \in\left(\max \left\{\frac{1}{2}, C\right\}, \frac{1+C}{2}\right], \alpha_{1} \in\left[0, \alpha_{2}-C\right)$ & $\left\{x_{1}^{*}, \alpha_{2}\right\}, x_{1}^{*} \in\left[0, \alpha_{2}-C\right] ;$ \\
\hline$C \in(0,1), \alpha_{1} \in\left[\frac{1-C}{2}, \min \left\{\frac{1}{2}, 1-C\right\}\right), \alpha_{2} \in\left(C+\alpha_{1}, 1\right]$ & $\left\{\alpha_{1}, x_{2}^{*}\right\}, x_{2}^{*} \in\left[\alpha_{1}+C, 1\right] ;$ \\
\hline$C \in\left(\frac{1}{2}, 1\right), \alpha_{1}=0, \alpha_{2} \in\left(\frac{1}{2}, C\right]$ & $\left\{0, \alpha_{2}\right\} ;$ \\
\hline$C \in\left(\frac{1}{2}, 1\right), \alpha_{2}=1, \alpha_{1} \in\left[1-C, \frac{1}{2}\right)$ & $\left\{\alpha_{1}, 1\right\} ;$ \\
\hline \hline & 2 equilibria: \\
\hline \hline$C \in(0,1), \alpha_{2} \in\left(\max \left\{\frac{1}{2}, C\right\}, \frac{1+C}{2}\right), \alpha_{1} \in\left[\alpha_{2}-C, \frac{1-C}{2}\right]$ & $\left\{\alpha_{1}, x_{2}^{*}\right\}, x_{2}^{*} \in\left(1-\alpha_{1}, 1\right]$, \\
& $\left\{x_{1}^{*}, \alpha_{2}\right\}, x_{1}^{*} \in\left[0, \alpha_{2}-C\right] ;$ \\
\hline$C \in(0,1), \alpha_{1} \in\left(\frac{1-C}{2}, \min \left\{\frac{1}{2}, 1-C\right\}\right), \alpha_{2} \in\left[\frac{1+C}{2}, \alpha_{1}+C\right]$ & $\left\{\alpha_{1}, x_{2}^{*}\right\}, x_{2}^{*} \in\left[\alpha_{1}+C, 1\right]$, \\
& $\left\{x_{1}^{*}, \alpha_{2}\right\}, x_{1}^{*} \in\left[0,1-\alpha_{2}\right) ;$ \\
\hline$C \in(0,1),\left\{\alpha_{1}=\frac{1-C}{2}, \alpha_{2}=\frac{1+C}{2}\right\} \cup\left\{x_{2}^{*}\right\}, x_{2}^{*} \in\left[\alpha_{1}+C, 1\right]$, \\
$\left\{\alpha_{1} \in\left(\frac{1-C}{2}, \min \left\{\frac{1}{2}, 1-C\right\}\right), \alpha_{2} \in\left(\max \left\{\frac{1}{2}, C\right\}, \frac{1+C}{2}\right)\right\}$ & $\left\{x_{1}^{*}, x_{1}^{*} \in\left[0, \alpha_{2}-C\right] ;\right.$ \\
\hline$C \in\left(\frac{1}{2}, 1\right), \alpha_{1} \in\left(0, \frac{1-C}{2}\right], \alpha_{2} \in\left(\frac{1}{2}, C\right]$ & $\left\{0, \alpha_{2}^{*}\right\} ;, x_{2}^{*} \in\left(1-\alpha_{1}, 1\right]$, \\
\hline$C \in\left(\frac{1}{2}, 1\right), \alpha_{1} \in\left(\frac{1-C}{2}, 1-C\right), \alpha_{2} \in\left(\frac{1}{2}, C\right]$ & $\left\{\alpha_{1}, x_{2}^{*}\right\}, x_{2}^{*} \in\left[\alpha_{1}+C, 1\right]$, \\
& $\left\{0, \alpha_{2}\right\} ;$ \\
\hline$C \in\left(\frac{1}{2}, 1\right), \alpha_{1} \in\left[1-C, \frac{1}{2}\right), \alpha_{2} \in\left(\frac{1}{2}, C\right]$ & $\left\{\alpha_{1}, 1\right\}$, \\
& $\left\{0, \alpha_{2}\right\} ;$ \\
\hline$C \in\left(\frac{1}{2}, 1\right), \alpha_{1} \in\left[1-C, \frac{1}{2}\right), \alpha_{2} \in\left(C, \frac{1+C}{2}\right)$ & $\left\{\alpha_{1}, 1\right\}$, \\
& $\left.\left.\left\{x_{1}^{*}, \alpha_{2}\right\}, x_{1}^{*} \in\left[0, \alpha_{2}-C\right] ;, 1\right\}, x_{1}^{*}, \alpha_{2}\right\}, x_{1}^{*} \in\left[0,1-\alpha_{2}\right) ;$ \\
\hline \hline
\end{tabular}

Table 1. Political equilibria for $C \in(0,1)$.

Values of the parameters $C, \alpha_{1}$ and $\alpha_{2}$ :

Political equilibria:

\begin{tabular}{ll}
\hline \hline$C=1, \alpha_{1}=0, \alpha_{2} \in\left(\frac{1}{2}, 1\right)$ & $\left\{0, \alpha_{2}\right\},\{0,1\} ;$ \\
\hline$C=1, \alpha_{2}=1, \alpha_{1} \in\left(0, \frac{1}{2}\right)$ & $\left\{\alpha_{1}, 1\right\},\{0,1\} ;$ \\
\hline$C=1, \alpha_{1} \in\left(0, \frac{1}{2}\right), \alpha_{2} \in\left(\frac{1}{2}, 1\right)$ & $\left\{\alpha_{1}, 1\right\},\left\{0, \alpha_{2}\right\},\{0,1\} ;$ \\
\hline$C=1, \alpha_{1}=0, \alpha_{2}=1$ & $\{0,1\}$. \\
\hline \hline
\end{tabular}

Table 2. Political equilibria for $C=1$. 


\section{References}

[1] Alesina, A., 1988. Credibility and Policy Convergence in a Two-Party System with Rational Voters. American Economic Review, 78, 796-805.

[2] Banks, J.S., 1990. A Model of Electoral Competition with Incomplete Information. Journal of Economic Theory, 50, 309-325.

[3] Besley, T., S. Coate, 1997. An Economic Model of Representative Democracy. Quarterly Journal of Economics, 112, 85-114.

[4] Calvert, R. L., 1985. Robustness of the Multidimensional Voting Model: Candidate Motivations, Uncertainty, and Convergence. American Journal of Political Science, 29, 69-95.

[5] Downs, A., 1957. An Economic Theory of Democracy. New York: Harper and Row.

[6] Feddersen, T.J., I. Sened, S.G. Wright, 1990. Rational Voting and Candidate Entry under Plurality Rule. American Journal of Political Science, 34, 1005-1016.

[7] Osborne, M.J., A. Slivinski, 1996. A Model of Political Competition with CitizenCandidates. Quarterly Journal of Economics, 111, 65-96.

[8] Palfrey, T.R., 1984. Spatial Equilibrium with Entry. Review of Economic Studies, 51, 139-156.

[9] Roemer, J.E., 1994. A Theory of Policy Differentiation in Single Issue Electoral Politics. Social Choice and Welfare, 11, 355-380.

[10] Wittman, D., 1977. Candidates with Policy Preferences: A Dynamic Model. Journal of Economic Theory, 14, 180-189.

[11] Wittman, D., 1983. Candidate Motivation: A Synthesis of Alternative Theories. American Political Science Review, 77, 142-157.

[12] Wittman, D., 1990. Spatial Strategies when Candidates have Policy Preferences. In: Enelow, J., Hinich, M. (Eds.), Advances in the Spatial Theory of Voting. Cambridge: Cambridge University Press. 